
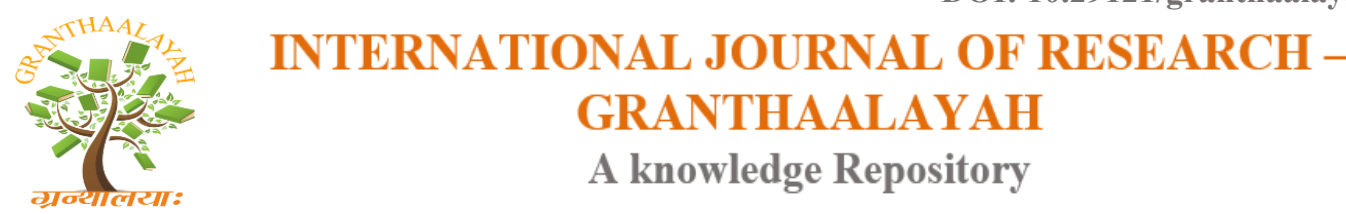

Science

\title{
A RELATIVE STUDY TO FIND OUT THE RISK POPULATION IN VINDHYAN REGION BY CARCINOGEN ACTIVATING AND DEACTIVATING THE GSTM1 POLYMORPHISM
}

\author{
Snehlata Pandey ${ }^{* 1}$, Dr. Pallavi Indurkar ${ }^{2}$, Arvind Tripathi ${ }^{3}$, Jitendra Thipathi ${ }^{4}$, Sanjeev \\ Dubey 5 \\ ${ }^{* 1,3,4}$ Center of Biotechnology studies school of Environmental Biology APSU Rewa M.P. \\ (486001), INDIA \\ ${ }^{2}$ Department of ENT SGMH Rewa M.P. (486001), INDIA \\ ${ }^{5}$ Department of Botany, Government Model Science College, Rewa, M.P. (486001), INDIA
}

\begin{abstract}
The Glutathione S-transferase are a family of phase II isoenzymes, believed to protect cells from reactive chemical intermediates and oxidative stress, resulting from a wide range of electrophilic xenobiotics (Example-PAH) and endogenous intermediates. Inheritance of null (gene deletion) alleles of the GSTM1 (chromosome 1p 13.3) genes is common in the population varies by ethnicity and is associated with the loss of enzymatic activity and cytogenetic damage. The studies have linked the gene deletion of GSTM1 to susceptibility to various cancers, including lung, bladder, Head, Neck, Colon and basal cell carcinoma. Variation in metabolism of carcinogens could increase or decrease exposure of cells to carcinogens. Ethnic variation in cancer incidence and mortality may be due in part because of differences in the distribution of polymorphisms, as well as differences in environmental and dietary exposures.
\end{abstract}

Keywords:

GSTM, gene polymorphism, carcinogen.

Cite This Article: Snehlata Pandey, Dr. Pallavi Indurkar, Arvind Tripathi, Jitendra Thipathi, and Sanjeev Dubey, "A RELATIVE STUDY TO FIND OUT THE RISK POPULATION IN VINDHYAN REGION BY CARCINOGEN ACTIVATING AND DEACTIVATING THE GSTM1 POLYMORPHISM" International Journal of Research - Granthaalayah, Vol. 4, No. 5 (2016): 133-138.

\section{INTRODUCTION}

Polymorphism is a process in which more than one allele occupies that gene's locus within a population. The Glutathione S-transferase are a family of phase II isoenzymes, believed to protect cells from reactive chemical intermediates and oxidative stress, resulting from a wide range of electrophilic xenobiotics (Example-PAH) and endogenous intermediates (Example- 
reactive oxygen species) $)^{(1,2,3,4,5,6,7)}$. Inheritance of null (gene deletion) alleles of the GSTM1 (chromosome 1p 13.3) genes is common in the population varies by ethnicity and is associated with the loss of enzymatic activity and cytogenetic damage. The studies have linked the gene deletion of GSTM1 to susceptibility to various cancers, including lung, bladder, Head, Neck, Colon and basal cell carcinoma ${ }^{(8)}$. Variation in metabolism of carcinogens could increase or decrease exposure of cells to carcinogens, and through this pathway affects susceptibility to cancer. These polymorphisms are often common, and that their prevalence differs between populations. Ethnic variation in cancer incidence and mortality may be due in part because of differences in the distribution of polymorphisms, as well as differences in environmental and dietary exposures.

\section{MATERIAL \& METHODS}

Study population: In our study we have selected the vindhyan region, the heart land of India. This is constructed by four district of Madhya Pradesh and is the oldest habitat of mankind. The Kol, Gond, Bhil and Baiga are the native tribe of this region. Modern population is dominated by Hindu and Mohammedan religions. The study population consisted of 409 unrelated subjects comprising between 311 hindus, 25 muslims and 73 tribals.

Blood sample collection: Blood samples were drawn by the intra-venous injection and 3-5ml. blood were collected in the EDTA containing bowls and were stored in the $-20^{\circ} \mathrm{C}$ till the used.

DNA isolation: Genomic DNA was extracted from whole blood by the modification of salting out procedure described by Miller. ${ }^{[9]}$

Detection of GSTM1 polymorphism via PCR: The Glutathione S-transferase (Located on chromosome 1p 13.3) show the homozygous deletion of the gene. The deletion of the gene was studied by the amplification of the gene with gene specific primer.

Genotyping: Genotyping was carried out by polymerase chain reaction (PCR) and restriction enzyme digestion. The GSTM 1 polymorphism was detected using the following primers: GSTM 1 F-5'GAA CTC CCT GAA AAG CTA AAG C3' and GSTM 1R-5'GTT GGG CTC AAA TAT ACG GTG G3'. The PCR was carried out in a final volume of $25 \mu \mathrm{l}$, containing $100 \mathrm{ng}$ of genomic DNA $(4-5 \mu \mathrm{l}), 2.5 \mu \mathrm{l}$ of $10 \mathrm{X}$ Taq polymerase buffer $(10 \mathrm{mM}$ Tris $\mathrm{HCl} \mathrm{pH} 8.8,50 \mathrm{mM}$ $\mathrm{KCl}, 1.5 \mathrm{mM} \mathrm{MgCl} 2,0.01 \%$ gelatin, $0.005 \%$ Tween-20, 0.005\% NP-40; final concent ration 1X; Genetix Biotech Asia Pvt. Ltd.,India), $1 \mu \mathrm{l}$ of $10 \mathrm{mM}$ dNTPs (Banglore Genei, Bangalore, India), $1 \mu \mathrm{l}$ of $25 \mathrm{pmol} / \mu \mathrm{l}$ of secific forward and reverse primers and $1 \mu \mathrm{l}$ of unit of $1 \mathrm{U} / \mu \mathrm{l}$ Red Taq DNA polymerase (Bangalore genei).

Thermal profile used for the amplification of desired segment of gene was as follows: Initial denaturation at $95^{\circ} \mathrm{C}$ for $5 \mathrm{~min}$ and 30 cycles of denaturation at $94^{\circ} \mathrm{C}$ for $45 \mathrm{Sec}$, annealing at $60^{\circ} \mathrm{C}$ for $45 \mathrm{sec}$ and extension at $72^{\circ} \mathrm{C}$ for $1 \mathrm{~min}$, followed by final extension at $72^{\circ} \mathrm{C}$ for $07 \mathrm{~min}$. PCR products were separated on $2 \%$ agarose gel (2\% w/v, SRL) using a 100 bp molecular weight (MW) marker to confirm the PCR product size of $215 \mathrm{bp}$. 


\section{STATISTICAL ANALYSIS}

Statistical analysis was done by comparing the distribution of genotype frequencies and allele frequencies for all polymorphisms in all groups of study subjects. The proportions of different genotypes for a gene in a population are known as genotype frequencies. The proportion of a genotype in a sample will be the ratio of the number of individuals having that genotype of the total number of individuals in the sample. The proportions of different alleles for a gene present in a population are known as allele frequencies. The proportion of an allele in a sample will be the ratio of number of occurrence of the investigated allele in the population to the total number of alleles. Data was analyzed using Microsoft Excel 2002, Microsoft Corporation and graphPad Instat program (GraphPad Software, San Diego California USA,Copyright 1992-1998 GraphPad Software Inc. (www.graphpad.com).

\section{RESULTS}

\section{Hardy - Weinberg equilibrium}

The genotype frequencies of each study group were tested to be in accordance with hardy Weinberg equilibrium using chi square test for independence. All the calculated values were compared with tabulated values and found that all the frequencies were in Hardy - Weinberg equilibrium (Table 4.1). The standard tabulated values was 3.8 at 1 degree of freedom and $\mathrm{P}=$ 0.05 level of significance.

Table 1: Values of Chi square test for Hardy-Weinberg equilibrium for GSTM1 gene in study population.

\begin{tabular}{|c|l|l|l|}
\hline \multirow{2}{*}{ Gene polymorphism } & \multicolumn{2}{|l|}{ Study Groups $(\chi 2$ Values $)$} \\
\cline { 2 - 4 } & Hindu & Muslims & Tribal's \\
\hline GSTM1 & 2.89487 & 3.72665 & 1.40445 \\
\hline
\end{tabular}

Determination of GSTM1 polymorphism, genotypes/Alleles frequencies and their association between study groups: The polymorphism in GSTM1 genes were detected by the amplification of $215 \mathrm{bp}$ DNA sequence by using specific primer. The presence of $215 \mathrm{bp}$ fragment in $2 \%$ agarose confirmed the wild type (Present) allele and absence of the PCR product on the gel were designated as Null allele (figure.1). 


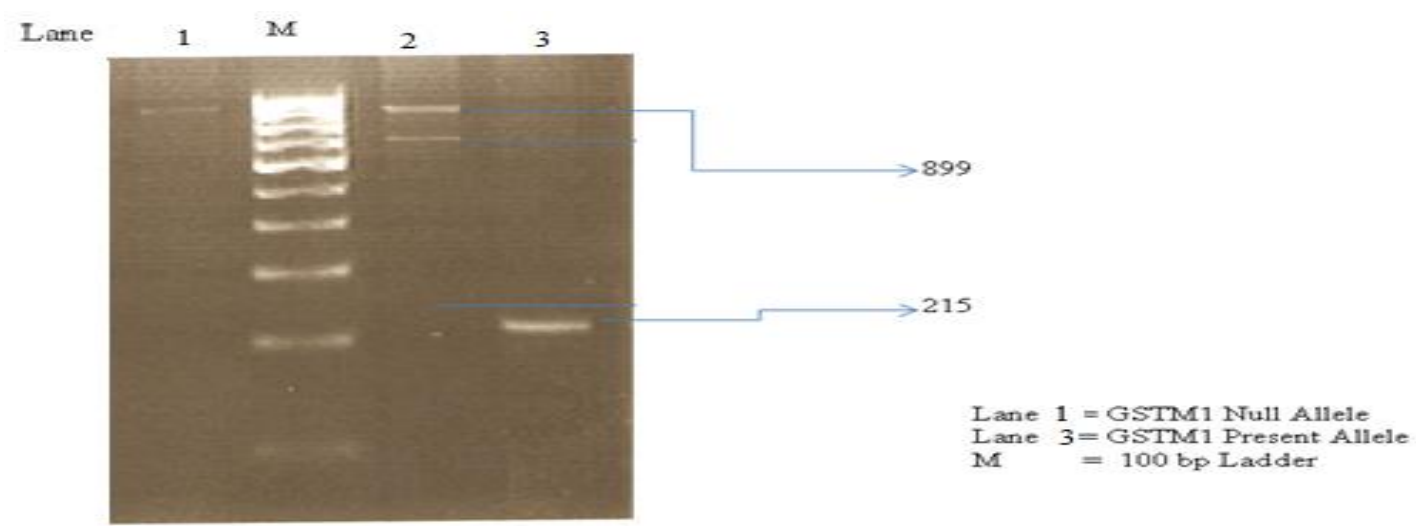

Figure 1 Gel image of GSTM1 with CYP1A 1

The allelic frequency of Present allele scored $49.52 \%, 44 \%$ and $52.05 \%$ in Hindu, Muslim and Tribal respectively. The frequencies of Null allele were scored $50.48 \%, 56 \%$ and $47.95 \%$ in Hindu, Muslim and Tribal subjects (Table2 and figure 2). The associations of allele frequencies between groups were tested by Fisher's exact test and values obtained were $\mathrm{P}=0.6797$ between Hindu - Muslim, $\mathrm{P}=0.6436$ between Muslim - Tribal and $\mathrm{P}=0.7949$ between Hindu - Tribal population. All the values were statically Non significant between all the groups tested (Table 2).

Table 2: Frequency distribution and association of Genotype / alleles of GSTM1 genes in study groups.

\begin{tabular}{|c|c|c|c|c|c|c|}
\hline \multirow{3}{*}{$\begin{array}{l}\text { GSTM1 genes } \\
\text { Genotypes/ Alleles }\end{array}$} & \multicolumn{6}{|c|}{ Study Groups } \\
\hline & \multirow{2}{*}{\multicolumn{2}{|c|}{$\begin{array}{l}\text { Hindu } \\
\text { No. } \quad \%\end{array}$}} & \multicolumn{2}{|c|}{ Muslim } & \multirow{2}{*}{\multicolumn{2}{|c|}{$\begin{array}{l}\text { Tribal } \\
\text { No. }\end{array}$}} \\
\hline & & & No. & $\%$ & & \\
\hline Present & $\begin{array}{l}154 \\
49.52\end{array}$ & & & 44 & $\begin{array}{l}38 \\
52.05\end{array}$ & \\
\hline Null & $\begin{array}{l}157 \\
50.48\end{array}$ & & & 56 & $\begin{array}{l}35 \\
47.95\end{array}$ & \\
\hline \multicolumn{7}{|c|}{ P- Values(Fisher's exact test) } \\
\hline Hindu- Muslim & \multicolumn{6}{|c|}{0.6797 (NS) } \\
\hline Muslim- Tribal & \multicolumn{6}{|c|}{0.6436 (NS) } \\
\hline Hindu-Tribal & \multicolumn{6}{|c|}{0.7949 (NS) } \\
\hline
\end{tabular}




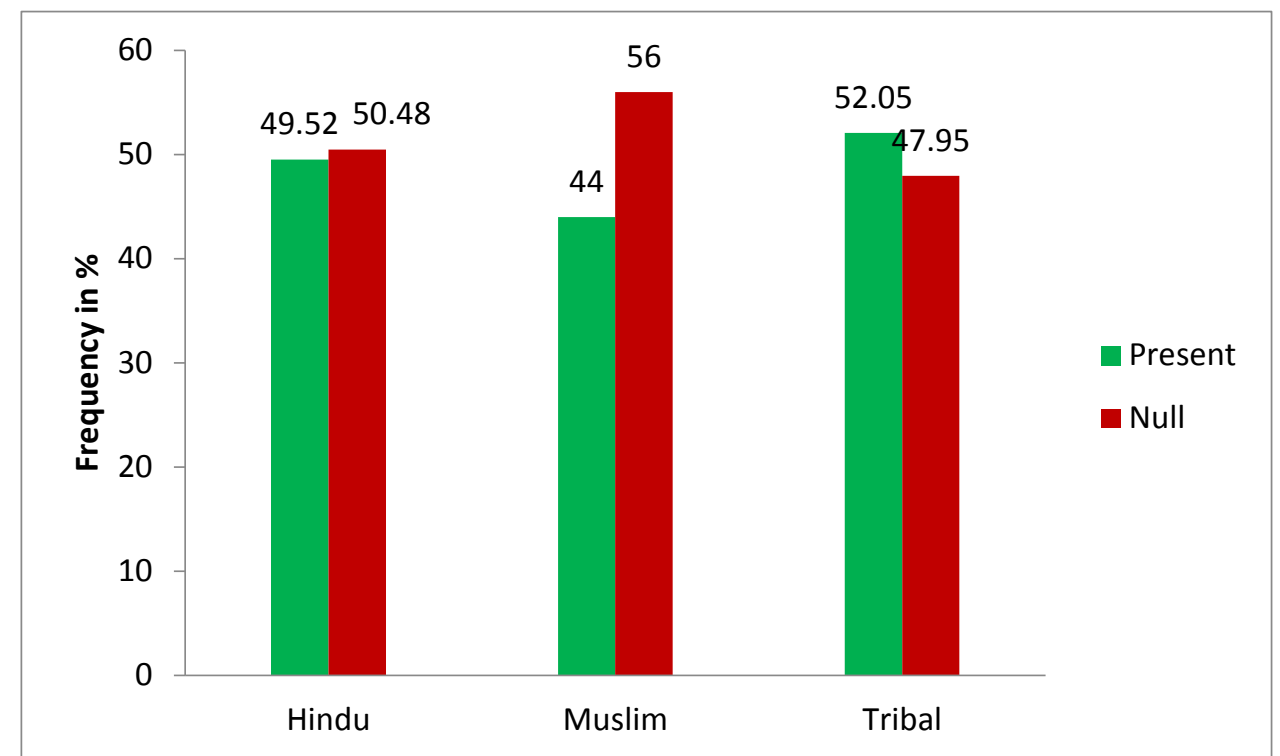

Figure 2: GSTM1 Allelic frequency in (in \%) study groups (Hindu, Muslim \& Tribal)

\section{DISCUSSION}

In past three decades the information about carcinogen metabolism has been improved. Due to this information the interest has grown about study of polymorphism among carcinogen activating and de-activating genes. In this respect we have conducted a broad polymorphism screening study in population of Vindhyan Region. The GSTM1 is important carcinogen metabolizing gene, as it is responsible for the metabolism of highly ubiquitous environmental carcinogen like Polycyclic Aromatic Hydrocarbon (PAH) which is also the most lethal constituent of cigarette smoke.

The allelic frequencies of Polycyclic aromatic Hydrocarbon (PAH) metabolizing gene was determined in a sample of typical population, which was stratified into three groups (Hindu, Muslim and Tribal) based on their ethnicity. The total 409 individuals were screened for the GSTM I Null/Present polymorphism, in which 311 individuals were Hindu, 25 individuals were Muslim and 73 individuals were Tribal.

The allele Frequency of GSTM1 were compared between the three groups of our study population and we found that the frequency distribution of Present and null allele were not statically different between these three groups, However the increase of Null allele frequency seen in Muslim than other groups. Where the frequency distribution of Present and Null allele were Present $=49.52 \%$ and Null $=50.48 \%$ in Hindu, Present $=44 \%$ and null $=56 \%$ in Muslim, and in tribal were Present $=52.25 \%$ and Null $=47.95 \%$.

A slight difference were seen when result from our study compared with the finding of KyoungMu Lee et al (186) in Asian population (present $=44.5$ and Null = 55.6) and finding of Valder R. Anuda et al (187) in Caucasian population (present $=45 \%$ and null $=55 \%$ ) which were corresponding to frequency in Muslim group of our population but different from Hindu and Tribal. These differences could be due to differences in mating pattern. 
Surprisingly higher differences were seen when our finding were compared with finding of gaspar et al (188) in Amerindian groups where the frequency of present allele were reported $96.1 \%$ to $64.2 \%$ and frequency of null allele were reported $35.8 \%$ to $3.9 \%$ in different five Amerindian groups (Xavante, Guarani, Ache, Wai Wai and Zoro). This indicated that Amerindian population is distinct from our population.

\section{ACKNOWLEDGMENTS}

We thank all the subjects who participated in this study.

\section{DECLARATIONS}

Funding: Non funding

Conflict of interest: Nil

\section{REFERENCES}

[1] Armstrong, R. N. (1997). Structure, catalytic mechanism, and evolution of the glutathione transferases. Chem. Res. Toxicol. 10, 2-18.

[2] Dirr, H. W., Reinemer, P. and Huber, R. (1994). X-ray crystal structures of cytosolic glutathione $S$-transferases. Implications for protein architecture, substrate recognition and catalytic function. Eur. J. Biochem. 220, 645-661.

[3] Wilce, M. C. J. and Parker, M. W. (1994). Structure and function of glutathione Stransferases. Biochim. Biophys. Acta 1205, 1-18.

[4] Hayes, J. D. and Pulford, D. J. (1995). The glutathione S-transferase supergene family:Regulation of GST and the contributions of the isoenzymes to cancer chemoprotection and drug resistance. CRC Crit. Rev. Biochem. Mol. Biol. 30, 445-600.

[5] Eaton, D. L. and Bammler, T. K. (1999). Concise review of the glutathione S-transferases and their significance to toxicology. Toxicol. Sci. 49, 156-164.

[6] Salinas, A. E. and Wong, M. G. (1999). Glutathione S-transferases - a review. Curr. Med. Chem. 6, 279-309.

[7] Edwards, R., Dixon, D. P. and Walbot, V. (2000). Plant glutathione S- $\quad$ transferases: Enzymes with multiple functions in sickness and health. Trends Plant Sci. 5,193-198.

[8] Janeric Seidegard, Ronald W. Pero, Daniel G. Miller and Edward J. Beattie (1986). A glutathione transferase in human leukocytes as a marker for the susceptibility to lung cancer. Carcinogenesis Vol. 7, No-5, 751-753.

[9] Miller SA, Dykes DD, Polesky HF. A simple salting out procedure for extracting DNA from human nucleated cells. Nucleic Acids Res. 1988; 16(3):1215. 